International Journal of Current Advanced Research

ISSN: O: 2319-6475, ISSN: P: 2319 - 6505, Impact Factor: SJIF: 5.995

Available Online at www.journalijcar.org

Volume 6; Issue 5; May 2017; Page No. 3616-3622

DOI: http://dx.doi.org/10.24327/ijcar.2017.3622.0332

\title{
EVALUATION OF DISCHARGE PROCESS OF INSURANCE VERSUS PAYING CATEGORY OF PATIENTS IN A HOSPITAL
}

\author{
Ramamohan D., GSCNV Prasad., G Sravana Kumar and N R Sahana Bhat
}

Narayana Medical College \& Hospital, Nellore, AP

\section{A R T I C L E $\quad$ I N F O}

\section{Article History:}

Received $7^{\text {th }}$ February, 2017

Received in revised form $12^{\text {th }}$ March, 2017

Accepted $28^{\text {th }}$ April, 2017

Published online $28^{\text {th }}$ May, 2017

\section{Key words:}

Discharge Summary, Insurance, Paying, Delays

\begin{abstract}
A B S T R A C T
Back ground: The discharge of patients in the hospital starts from the clearance given by the treating doctors during their rounds and the final step is the patient leaving the hospital. The discharge of Dr NTR VSP patients, being under the Insurance scheme of the government, should follow guidelines of documentation, information and approvals in the system which leads to delays when compared to payment category of patients. This leads not only to dissatisfaction among patients and attendees but also has impact on costs of stay, treatment costs and other overheads. There is a need to identify the factors responsible for bottlenecks and suggest measures for improvised patient care and patient satisfaction and at the same time reduce costs to the hospital and patient.

Methods: A pilot study is conducted to identify the sequence of activities in the VSP and paying patients' discharges. Focussed group discussions are done with VSP staff \& Nurses and opinion surveys taken to analyse the reasons responsible for delays by ranking the reasons in order. Retrospective study of statistics for number of discharges and prospective study to confirm and compare steps between VSP and paying procedures and identify bottle necks and measures to reduce delays.

Results: The VSP discharge process has more steps in discharge process when compared to paying discharge process due to the need to follow insurance guidelines as per the MOUs. The documentation and evidences need to be recorded in the case sheet as well as in the Aarogyasri trust online as compared to the simple and direct steps for paying type of discharges.Opinion of staff nurses on paying mode of discharge. Ranking in order top three reasons are 1. Finalisation of discharge summary by the doctor. 2. Patient and their attendees waiting or making arrangements for transport to leave the hospital 3. Finalisation of the bill by billing section

The opinion of staff nurses on insurance process revealed and Ranking order top three reasons are 1. Finalisation of Discharge by the doctor 2. Verification of case sheet By VSP staff 3. Indenting and procurement of medicines The opinion of insurance staff on insurance discharge: Ranking in order top three reasons are 1. Handing over of the case sheet from ward to insurance office 2. Case sheet received by ins top three reasons are ce office and Finalisation of discharge summary by the doctor 3 . Shifting of patient from ward for mithra photo.

Conclusions: The discharges should be planned in advance and should utilise the data available in the system since admission starting from demographic data, investigations, progress notes, treatment advised, operation notes etc, which are tracked and documented in the case sheet at every service level during the stay in the hospital. Coordinator and floor in charges along with cooperation of Nursing and Billing can reduce delays and for patient satisfaction
\end{abstract}

Copyright $(2017$ Ramamohan D et al. This is an open access article distributed under the Creative Commons Attribution License, which permits unrestricted use, distribution, and reproduction in any medium, provided the original work is properly cited.

\section{INTRODUCTION}

\section{Problem statement}

It is very common tendency for the patient and attendees to be eager to leave the hospital premises with their illness relieved, once the admitting doctor gives fitness for discharge. The hospital has various sequence of activities, procedures, documentation, financial clearance, involving both medical and non medical departments like billing, In Patient services, medical records, credit clearances etc depending on the 'Type of payment status' at the time of admission.

\section{*Corresponding author: Ramamohan D}

Narayana Medical College \& Hospital, Nellore, AP scheme of the Govt of Andhra Pradesh) and Direct payment (out of Pocket) patients. A pilot study has been conducted to understand the discharge process for insurance and paying patients. It is found that relatively more time is taken up for Insurance (VSP) patients when compared to paying category patients. The aim of the study is to understand the sequence of steps observed for both types of discharges. Factors affecting or contributing for delays are identified and measures or means are suggested to reduce delays, ultimately aiming at quality care, patient's satisfaction and reputation of the hospital.

\section{Objectives}

1. To study the discharge process of VSP patients and to draw flow chart of sequence of steps. 
2. To identify factors responsible for delays and compare with the Payment category of patients.

3. To suggest measures for improvement for better patient satisfaction.

\section{METHODOLOGY}

The pilot study is done to understand and depict the activities in the discharge process of patients. After understanding the sequence of steps and activities in the discharge process, a flow chart is prepared. A Prospective study for a period of one month April 2016 is undertaken to evaluate the sequence of steps of activities observed during pilot study and also to frame and collect questionnaire related to reasons for delays in the discharge process from various stake holders involved i.e. insurance staff, nursing in charges and nursing supervisors, administration,

At the same time the process of discharge for the payment category patients is studied and sequence of steps are drawn.

The discharge statistics are collected from the Billing department for a period of three months to know the average number of discharges.

The factors contributing for delays are identified with the Personal interview of the VSP Medical officers, treating doctors, Ward in charges, VSP PROs and Aarogya Mithras and others who are involved in the total process.

Primary data is collected through focused group interviews of VSP staff, Nursing, Billing, and Personal interview of and doctors / care providers to understand the scales, causes and consequences of ineffective discharge process.

The Reasons for delays are identified, and ranked through a questionnaire submitted to all the stake holders in this process.

Interventions should be targeted to minimise the delays at various steps and sometimes requires redesigning the operational aspects of the care to enhance operational efficiency and patient satisfaction.

\section{Limitations}

1. Establishing the causal relationship for various reasons and causes for delays of discharge process shall only be established by Time and motion studies and other operational research studies unlike the present study which is descriptive in nature and only opinion of the stakeholders

2. The subjective bias shall always exist and differences between the employees may affect the answers given for the reasons in delays in discharges

\section{LITERATURE REVIEW}

Demand for Inpatient beds will always be linked to the bed turnover which depends on the timelines of discharges from various wards or areas of the hospital. Especially specific departments like General medicine, orthopaedics, surgery, cardiology, neurology, Neurosurgery requires more number of vacant beds due to the admissions through emergency and trauma.

Medical issues Delayed diagnostic services, delayed medical consultation, elderly patients living alone are more likely reasons for delay in discharges in acute care areas. ${ }^{6}$

Reasons for discharge delays in teaching hospitals include waiting for results of the special tests advised by cross consultations or for results of already performed tests to be released, delay in clinical case discussion and providing specialised consultations which need to be attended to by process managers with involvement and understanding by the clinicians and specialists. ${ }^{6}$

Social factors An integrated literature review revealed organisational factors responsible for the delayed discharges from intensive care units due to increased adverse events that lead to higher costs. Inter disciplinary and multifaceted approach to the whole patient flow process is suggested to reduce delays. $^{7}$

Competitive edge: The discharge summary reflects the total treatment provided and period of stay in the hospital hence there is a need to positively project the hospital to gain competitive edge over other service providers.

The affects of delay in discharges mirror through the Patient or patient's attendees dissatisfaction and increased cost both to the patient and hospital.

\section{The Process}

The discharge process should start from the point of Admission itself as demographic data \& blanket consent can be tracked in the system which becomes part of discharge summary along with initial diagnosis and suggested investigations either at OPD or from Emergency.

The first step in the process is the decision by the treating doctor to give fitness to the patient for discharge from the hospital and counsel the patient and their attendees. Once they are convinced and agree for discharge, the process is initiated by the doctor. The Resident doctor completes the discharge notes, progress notes, investigations in brief, treatment given, medication advised, Operation notes if it is a surgical case, follow up advice, follow up medication, warning signs and symptoms, etc. The final summary is then checked, corrected, and signed by the consultant.

On the other hand the administrative aspects include final billing and payment by the patient or attendees and get billing clearance. The Insurance patients are given clearance only after documentation formalities. The pharmacy returns and refunds is another aspect before discharging the patient.

The total process involves different categories of employees starting from doctors, sisters, insurance staff, billing clerk, computer operators and supervisors. It is imperative that everyone should understand the criticality and after effects and cooperate with each other. Coordination is the key responsibility of floor in charge or discharge coordinator. 
The communication between and among individuals should be focussed to overcome barriers and effective in control of the limitations or bottlenecks

The process or logistic issues; The process involves movement of various documents especially records, reports, medico legal, updated billing charts, OT photos, insurance sanctioned authorisation letters, and approvals, discharge summary etc for which the responsible departments are strategically located at different floors of the hospital have to work in coordination to speed up the process of discharge

Hospital factors The documents needs to be carried physically from the wards to billing and records department and leads to delays due to non availability of staff, or key staff absence for taking right decision at right time, human resources involved, their knowledge and attitudes and level of coordination plays major part in hastening the process of discharge process.

Physician and Nurses role: The patients are more attached to the admitting doctor and the nurse who accompanies throughout the stay in the hospital and they in turn have to educate, counsel and appraise the queries and worries, till they leave from the hospital and even follow up reviews and advice by nurses' counselling. The check list for clearance from billing or pharmacy is the responsibility of duty nurse or supervisor. billing clearance \& Follow up drugs and " No Dues " needs to be verified and patient is permitted to leave from the ward after Security clearance. Duty nurses tracking the discharge requirements, clearance is essential at every stage of discharge.

Communication between consultant and intern or Asst. Physician: Frequent interaction between the consultant and the asst doctors team in finalising the discharge medication and advice and authorised signature on the summary. Ongoing communication between physicians, nurses, administration is required for effective process .ways and means of communication is also needs attention among the staff and patient attendees. Pharmacy, returns \& refunds: The return of drugs and refund of money paid in advance contributes for significant time to settle as responsible administrative employee has to approve or authorise especially after working hours.or holidays. Non availability of key staff leads to delays and patient dissatisfaction and conflicts between staff and patients. The travel and transport arrangements by the patient and attendees might become issue for delay as usually the discharge process was completing after routine working hours.

Documentation and filing: This is the hospital requirement to preserve the documents for audit or research or for verification at later date for stipulated period as per statutory requirements. Missing of some important documents / credit papers / sanctioned letters leads to financial loss to the hospital as they are required to be submitted to the TPA or insurance company or organization.

Morning discharge rounds by the admitting doctor along with duty nurse, resident doctor and floor supervisor and discharge coordinator is advised and monitoring the activities, identifying limitation Hardware and machines; the functioning of computer systems, online data, printers and software issues and break down of these at required time leads to anxiety, tension and conflicts and contributes to delays of discharge.

\section{RESULTS AND DISCUSSION}

Hospitalisation process has three main stages Admission, inpatient period and discharge process. The admissions are of two types- Elective admissions from Outpatient department and through Emergency or casualty. ${ }^{1}$

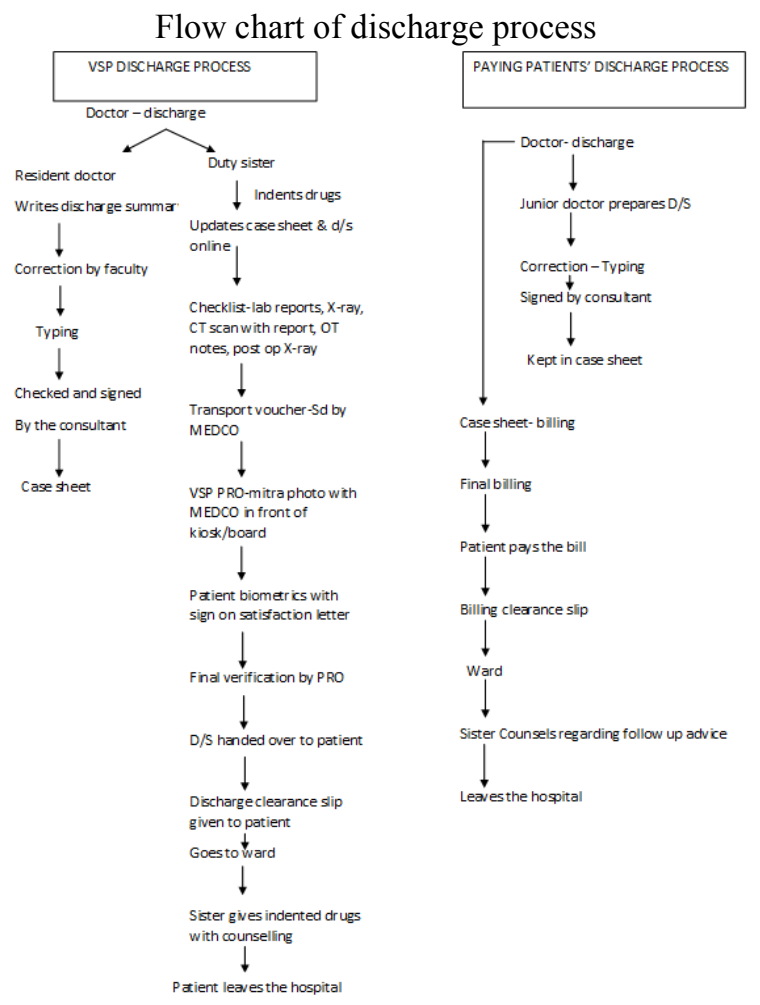

The additional steps involved in the VSP discharge when compared with paying are 1. Mithra photo with MEDCo at Kiosk 2. Transport voucher with payment 3. Patient biometrics in the system 4 . Indenting and issuing discharge medicines. AS these are required in the process of insurance which are respnsible for dealys in dischrge.

Information is the foundation of any patient flow initiative and is built upon the capture, integration and sharing of information both within and across the different departments and staff ${ }^{2}$. Hospitals can combine process management with IT for better outcome in the discharge process. ${ }^{3}$ The efficient discharge process is required for effective utilisation of beds and Bed management and hospital throughout .The delays can be classified, Organizational, Technical and Individual levels. Discharge information should be accurate and understood by patients and their community counter parts. Discharge templates prepared in advance will definitely standardise the components of summary which reflects the reputation of the hospital.

Medication: Procurement of medicines by indenting by duty nurse, availability of drugs, billing, communication and logistic issues are responsible for delays at every stage. Ultimately the nurse will counsel the patient regarding the usage of discharge prescription. Liaison between nurse pharmacists is the critical step in this process.

Regular ward visit: Frequent tracking by the duty doctor or resident is essential to monitor the discharge process as the finalisation of the discharge summary, clarification of queries 
by patients and their attendees, discharge advice or follow up guidelines need to be explained by the admitting doctor .

Table- 1 Opinion on VSP Discharges by VSP Staff $(n=22)$

\begin{tabular}{ccccccccccccc}
\hline Q Rank & Q1 & Q2 & Q3 & Q4 & Q5 & Q6 & Q7 & Q8 & Q9 & Q10 & Q11 & Q12 \\
\hline 1 & 3 & $\mathbf{8}$ & 2 & 2 & 0 & 1 & 0 & 3 & 1 & 0 & 2 & 0 \\
2 & $\mathbf{4}$ & 4 & $\mathbf{4}$ & 0 & 3 & 1 & 3 & 1 & 1 & 1 & 0 & 0 \\
3 & 4 & 1 & 3 & 0 & 4 & 0 & 3 & $\mathbf{6}$ & 0 & 0 & 1 & 0 \\
4 & 0 & 3 & 3 & 2 & $\mathbf{3}$ & $\mathbf{3}$ & 2 & 5 & 1 & 0 & 0 & 0 \\
5 & 2 & 3 & 1 & $\mathbf{6}$ & 2 & 0 & 3 & 2 & 0 & 1 & 1 & 1 \\
6 & 3 & 0 & 3 & 1 & 3 & 3 & 2 & 3 & 0 & 3 & 0 & 1 \\
7 & 3 & 1 & 2 & 1 & 5 & 1 & 1 & 0 & 5 & 0 & 2 & 0 \\
8 & 1 & 1 & 3 & 5 & 0 & 2 & 3 & 0 & 0 & 1 & 2 & 4 \\
9 & 0 & 0 & 0 & 3 & 0 & 4 & 0 & 2 & 4 & 6 & 1 & 3 \\
10 & 1 & 0 & 1 & 1 & 1 & 0 & 2 & 0 & 3 & 6 & 3 & 4 \\
11 & 0 & 1 & 0 & 1 & 1 & 2 & 3 & 0 & 3 & 2 & 3 & 6 \\
12 & 1 & 0 & 0 & 0 & 0 & 5 & 0 & 0 & 2 & 2 & $\mathbf{7}$ & 3 \\
\hline
\end{tabular}

Opinion of VSP staff on Insurance mode of discharge of the patients: Bar chart

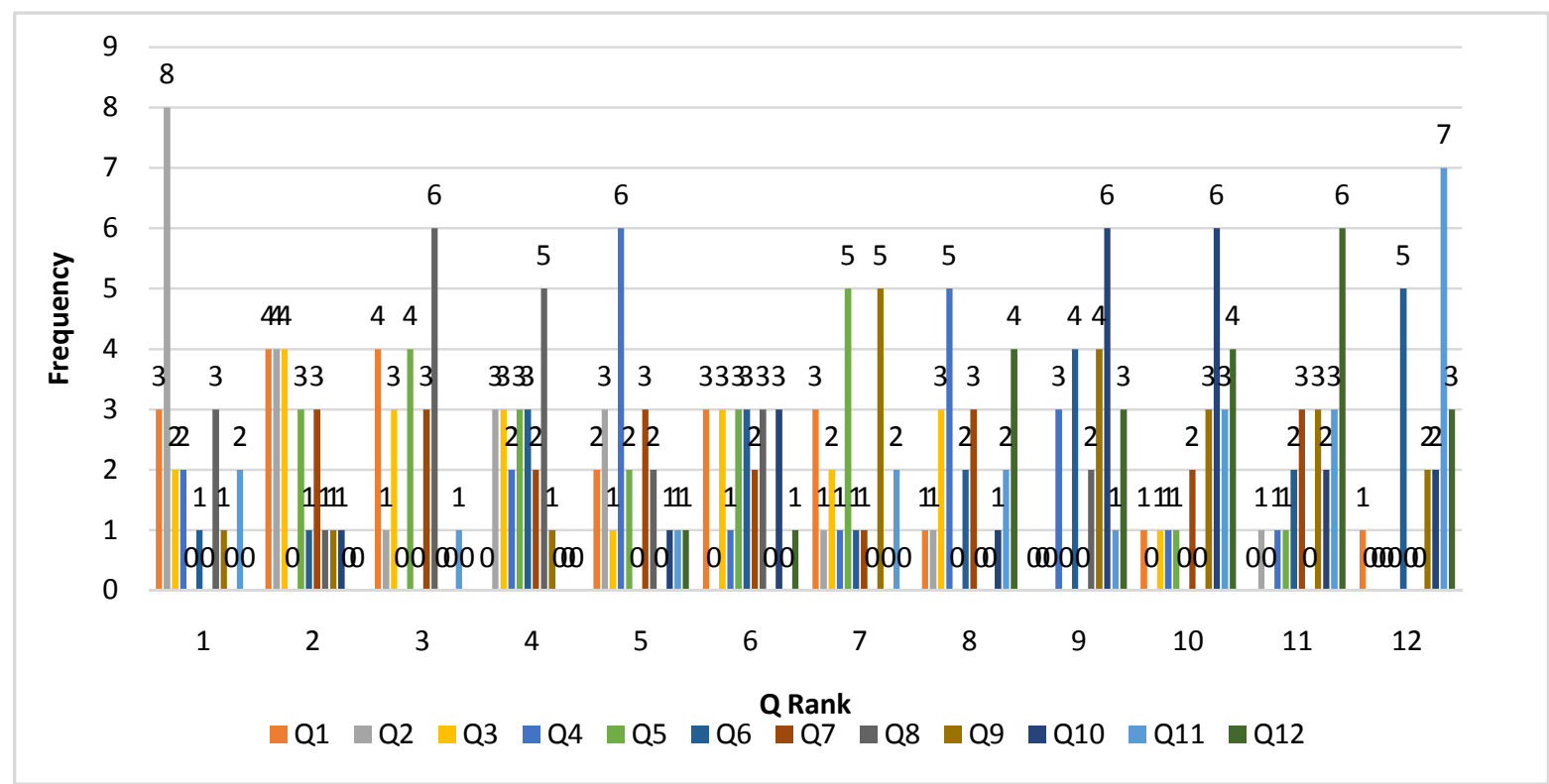

\section{Bar chart 1}

Teach back: It is advisable to always be assured that the right information is understood by the patient or the attendees to achieve desired result of discharge of the patients.

Communication errors between care givers and multiple receiving divisions like billing department, insurance, pharmacy, nursing staff and administration are to be identified and need immediate corrective actions.

The study also revealed lot of coordination is required between insurance staff and Nursing staff in facilitating discharge process.

Question analysis and Ranking for Reasons of Delays for discharges

Frequency table and Validity or Ranking for the Questions

\begin{tabular}{cccccc}
\hline \multicolumn{6}{c}{ Q2 } \\
Frequency & Percent & $\begin{array}{c}\text { Valid } \\
\text { Percent }\end{array}$ & $\begin{array}{c}\text { Cumulative } \\
\text { Percent }\end{array}$ \\
\hline \multirow{6}{*}{ Valid } & 1 & 8 & 36.4 & 36.4 & 36.4 \\
& 2 & 4 & 18.2 & 18.2 & 54.5 \\
& 3 & 1 & 4.5 & 4.5 & 59.1 \\
& 4 & 3 & 13.6 & 13.6 & 72.7 \\
& 5 & 3 & 13.6 & 13.6 & 86.4 \\
& 7 & 1 & 4.5 & 4.5 & 90.9 \\
& 11 & 1 & 4.5 & 4.5 & 95.5 \\
& 1 & 4.5 & 4.5 & 100.0 \\
\hline
\end{tabular}


for delays of Insurance discharges

Handing over of case sheet from WARD to VSP Office: Q2 Q2

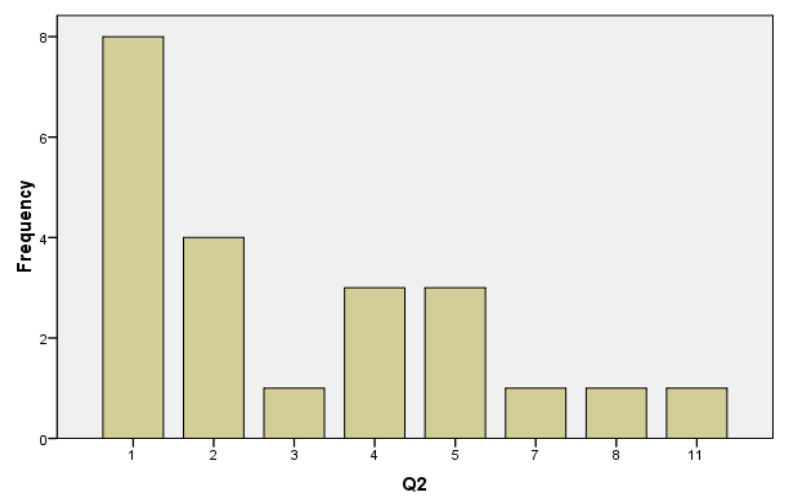

The insurance staff opined that the Handing over of the case sheet is number one reason for delay of the discharge process as against the Nursing staff opinion on the finalization of discharge summary by the doctors. The resident doctor has to write the draft of discharge summary only after completion of total rounds of the consultant or the senior doctors. 
Incomplete or incorrect information needs special attention and should be handled by a right person at the right time.

Policy makers or administrators should understand the ground realities and delegate the powers to the departmental heads especially billing head and Assistant managers involved in the discharge process to facilitate smooth function of discharge process. ${ }^{4}$ Discharged patients with medication on hand needs Teach back by patient and attendees to reduce review times and to help identify and guide high risk patients to suggest alert signs and symptoms. The summary should mention the name of the person and contact number in case of emergency.

Table 3:Opinion of nursing staff on VSP discharge process $(n=30)$

\begin{tabular}{ccccccccccccc}
\hline Rank & Q1 & Q2 & Q3 & Q4 & Q5 & Q6 & Q7 & Q8 & Q9 & Q10 & Q11 & Q12 \\
\hline 1 & 12 & 3 & 0 & 2 & 2 & 1 & 0 & 1 & 0 & 2 & 5 & 2 \\
2 & 2 & 3 & 1 & 5 & 4 & 3 & 1 & 2 & 1 & 1 & 3 & 4 \\
3 & 0 & 0 & 1 & 4 & 4 & 4 & 4 & 2 & 3 & 4 & 0 & 4 \\
4 & 1 & 1 & 3 & 2 & 1 & 7 & 2 & 5 & 3 & 1 & 0 & 4 \\
5 & 1 & 1 & 6 & 4 & 1 & 0 & 3 & 3 & 4 & 2 & 5 & 0 \\
6 & 0 & 4 & 5 & 1 & 3 & 1 & 4 & 3 & 3 & 2 & 3 & 1 \\
7 & 3 & 3 & 1 & 3 & 4 & 4 & 0 & 3 & 3 & 2 & 1 & 3 \\
8 & 0 & 2 & 1 & 2 & 3 & 4 & 4 & 3 & 1 & 6 & 2 & 2 \\
9 & 2 & 2 & 4 & 2 & 2 & 0 & 3 & 2 & 6 & 3 & 4 & 0 \\
10 & 1 & 3 & 3 & 1 & 2 & 2 & 2 & 4 & 3 & 4 & 2 & 3 \\
11 & 5 & 5 & 4 & 4 & 1 & 2 & 1 & 1 & 2 & 2 & 2 & 1 \\
12 & 3 & 3 & 1 & 0 & 3 & 2 & 6 & 1 & 1 & 1 & 3 & 6 \\
\hline
\end{tabular}

The opinion of staff nurses on insurance process revealed and Ranking order 1. Finalisation of Discharge by the doctor 2 . Verification of case sheet By VSP staff 3. Indenting and procurement of medicines 4. Mithra photo with MEDCO at kiosk 5. Case sheet receved by insurance PRO at Insurance office

The opinion of insurance staff on insurance discharge: Ranking in order 1. Handing over of the case sheet from ward to insurance office 2. Case sheet received by insurance office and Finalisation of discharge summary by the doctor 3 . Shifting $\mathrm{f}$ patient from ward for mithra photo 4. Indenting medicines and procurement from pharmacy 5. Case sheet verification by insurance staff

Frequency Table 4

\begin{tabular}{|c|c|c|c|c|c|}
\hline \multicolumn{6}{|c|}{ Q1 } \\
\hline & & Frequency & Percent & $\begin{array}{c}\text { Valid } \\
\text { Percent }\end{array}$ & $\begin{array}{c}\text { Cumulative } \\
\text { Percent }\end{array}$ \\
\hline \multirow{10}{*}{ Valid } & 1 & 12 & 40.0 & 40.0 & 40.0 \\
\hline & 2 & 2 & 6.7 & 6.7 & 46.7 \\
\hline & 4 & 1 & 3.3 & 3.3 & 50.0 \\
\hline & 5 & 1 & 3.3 & 3.3 & 53.3 \\
\hline & 7 & 3 & 10.0 & 10.0 & 63.3 \\
\hline & 9 & 2 & 6.7 & 6.7 & 70.0 \\
\hline & 10 & 1 & 3.3 & 3.3 & 73.3 \\
\hline & 11 & 5 & 16.7 & 16.7 & 90.0 \\
\hline & 12 & 3 & 10.0 & 10.0 & 100.0 \\
\hline & Total & 30 & 100.0 & 100.0 & \\
\hline
\end{tabular}

Bar Chart: 5

Q1

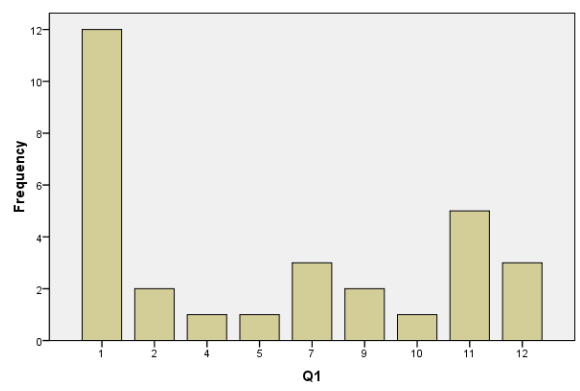

Standardisation of admission and discharge process is largely in hospital management control as well as on the attitudes and willingness of all the categories of staff involved in the discharge process. ${ }^{5}$

Table 5 Opinion of Nursing staff on paying mode of Discharges $(\mathbf{n}=30)$

\begin{tabular}{ccccccccccc}
\hline Q Rank & Q1 & Q2 & Q3 & Q4 & Q5 & Q6 & Q7 & Q8 & Q9 & Q10 \\
\hline 1 & 13 & 4 & 3 & 2 & 0 & 1 & 1 & 0 & 1 & 5 \\
2 & 1 & 3 & 5 & 3 & 0 & 4 & 4 & 0 & 2 & 8 \\
3 & 2 & 1 & 3 & 2 & 3 & 6 & 3 & 2 & 4 & 3 \\
4 & 7 & 1 & 2 & 6 & 2 & 2 & 4 & 2 & 3 & 1 \\
5 & 2 & 2 & 0 & 4 & 3 & 7 & 4 & 2 & 2 & 5 \\
6 & 0 & $\mathbf{5}$ & 5 & 3 & 3 & 2 & 7 & 3 & 2 & 1 \\
7 & 4 & 4 & 5 & 3 & $\mathbf{9}$ & 1 & 0 & 2 & 1 & 2 \\
8 & 1 & 2 & $\mathbf{3}$ & 2 & 7 & 3 & 4 & 2 & 4 & 2 \\
9 & 0 & 2 & 3 & 1 & 2 & 4 & 0 & $\mathbf{1 0}$ & 4 & 3 \\
10 & 0 & 6 & 1 & 4 & 1 & 1 & 3 & 7 & $\mathbf{7}$ & 0 \\
\hline
\end{tabular}

Opinion of nursing staff on paying mode of dischargesBAR Chart 6

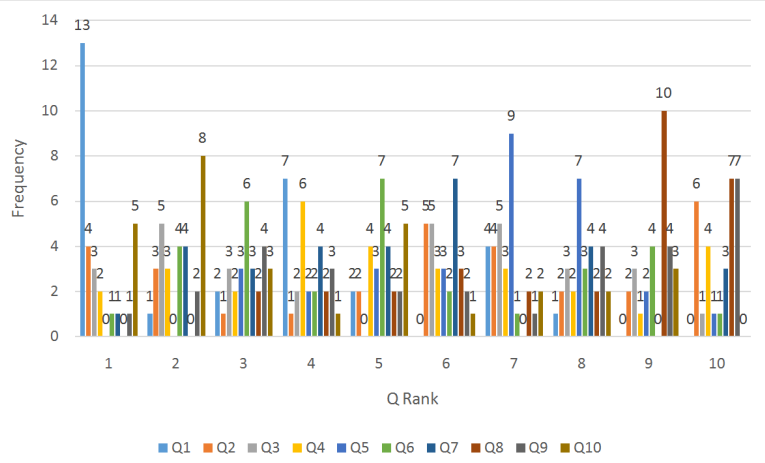

Frequency Table: 6 - question analysis for reasons for Delays of PAYING mode of discharges of patients in a hospital

\begin{tabular}{|c|c|c|c|c|c|}
\hline \multicolumn{6}{|c|}{$\begin{array}{l}\text { Q1. Finalisation of Discharge summary by the admitting } \\
\text { doctor }\end{array}$} \\
\hline & & Frequency & Percent & $\begin{array}{c}\text { Valid } \\
\text { Percent }\end{array}$ & $\begin{array}{l}\text { Cumulative } \\
\text { Percent }\end{array}$ \\
\hline \multirow{8}{*}{ Valid } & 1 & 13 & 43.3 & 43.3 & 43.3 \\
\hline & 2 & 1 & 3.3 & 3.3 & 46.7 \\
\hline & 3 & 2 & 6.7 & 6.7 & 53.3 \\
\hline & 4 & 7 & 23.3 & 23.3 & 76.7 \\
\hline & 5 & 2 & 6.7 & 6.7 & 83.3 \\
\hline & 7 & 4 & 13.3 & 13.3 & 96.7 \\
\hline & 8 & 1 & 3.3 & 3.3 & 100.0 \\
\hline & Total & 30 & 100.0 & 100.0 & \\
\hline
\end{tabular}

Opinion of staff nurses on paying mode of discharge.

Ranking in order 1. Finalisation of discharge summary by the doctor. 2. Patient and their attendees waiting or making arrangements for transport to leave the hospital 3. Finalisation of the bill by billing section 4 .Verification by the billing department 5. Payment by the patients and getting billing clearance

Bar Chart 7 - question analysis for Reasons of Delays in paying mode of discharges of patients in the hospital

Q1. Finalisation of Discharge summary by the admitting doctor 
Q1

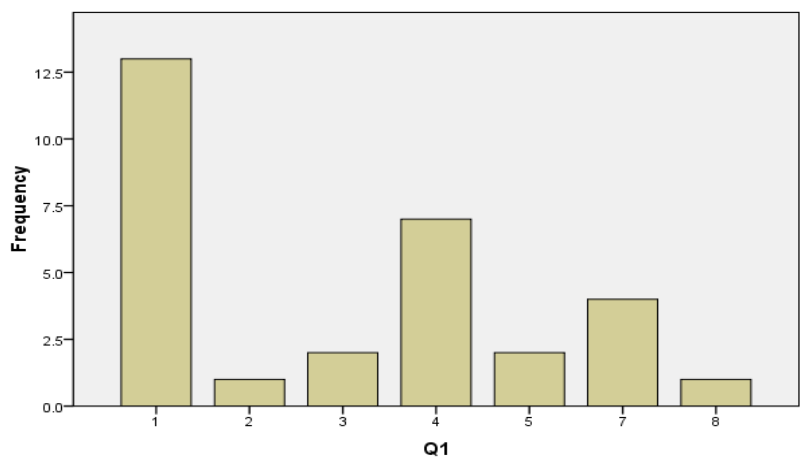

Optimum bed management is a strategic vision as provision of inpatient bed, staff engaged and supplies involved like diet, drugs and diagnostics is expensive. Rationalising the discharge process in terms of activities and timelines definitely alleviates the expenses and time involved.

Shifting of patients from ER, OT, ICUs and post operative wards to (general) wards may be hindered due to improper management of discharges from the general wards.

Making staff understand the consequences: All the stake holders involved in the discharge process starting from the admitting doctor, resident doctors, nurses, computer operators, data entry clerks, billing executives, Insurance staff, housekeeping, security, laboratory, pharmacy etc should understand the total discharge process and contribute and cooperate to hasten up and reduce delays and make patient and attendees comfortable while leaving the hospital.

\section{Conclusion and recommendations}

- Identifying patients who require early discharge: high priority should be given to the patients requiring early discharge due to clinical or social reasons.

- Hospital design: The design aspect of the hospital contributes to the delays as the process involves different departments situated at different floors of the hospital. Even though "single window system" cannot be assured, utilizing the technology in the form of System generated reports and advance entry of data since admission of the patient definitely reduces the delays.

- Discharge should be treated more like admissions and the similar enthusiasm shown from admission should be continued at every stage of Inpatient stay i.e. during further investigation, medication, surgery or procedures and documenting correct progress notes and advice and discharge summary.

- The junior residents / senior residents at the time of admissions should spend more time to get more information with detailed documentation so that discharge is made easy.

Follow up phone calls to patients: To have continuity of care and to reduce readmissions or unnecessary admissions it is advised to have a communication system of getting information of the status of patients after discharge and reminding about follow up appointments or reviews.

The floor coordinators: Nursing supervisor and the administrators should focus on this important issue with the following managerial aspects

- Motivation staff: To focus on their attitude and willingness and to be empathetic.

- System support: Hardware and logistic issues

- Co-ordination and co-operation: Between all stake holders and different group of employees of different cadres

- Effective communication: (inter disciplinary) and inter departmental, especially between Nursing, Billing and insurance division.

- Use of technology / software: Data from laboratory, pharmacy and electronic medical record can be retrieved from HIS for proper discharge summary

- Administration support: The senior management should provide enough support as it reflects the reputation of the hospital.

- Discharge planning criteria and advice should be given one day in advance by the Doctor

- Monitoring and tracking: By floor supervisors, nursing supervisors and administration.

- Supervision: Regular monitoring and evaluating all the activities and identifying reasons for delays and corrective action

- Check list: Of sequence of steps ensures accountability and responsibility for the staff. Missing documents can be identified immediately and corrective measures can be implemented

Further studies are required to measure the time lines through work study for various sequence of steps in both types of discharges

Ethical clearance: The study protocol has been submitted to the Institutional ethics committee and has been approved. There are no subjects involved in the study and only data is collected and opinion survey is evaluated without any interventions or procedures.

Conflict of interest: There is no conflict of Interest between the authors in any form or with any other individuals of the organisation.

\section{Acknowledgement}

We acknowledge the support of administration, insurance staff, nursing and other departmental heads and the clinicians involved in the direct as well as indirect patient care.

\section{ANNEXTURE I:}

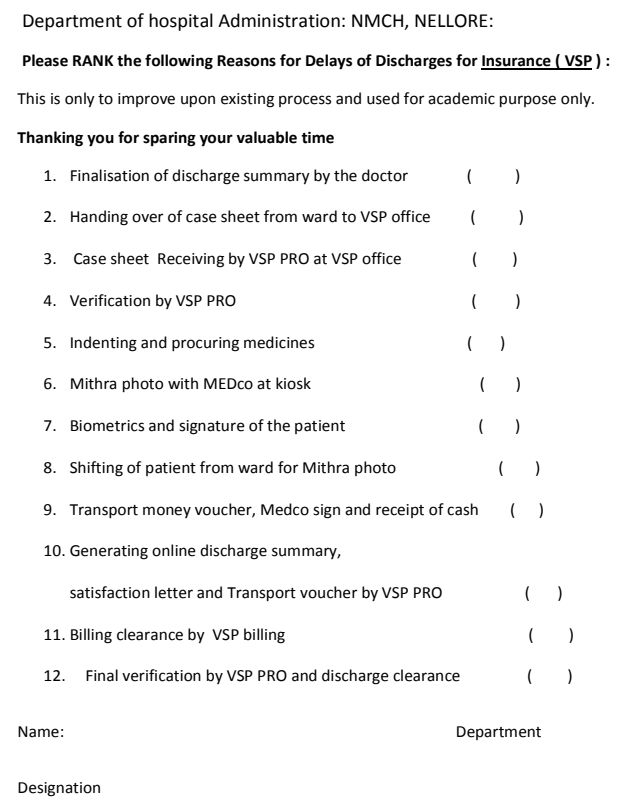


ANNEXTURE II:

Department of hospital Administration: NMCH, NELLORE:

\section{Please RANK the following Reasons for Delays of Discharges for PAYING cases}

This is only to improve upon existing process and used for academic purpose only.

\section{Thanking you for sparing your valuable time}

1. Finalisation of discharge summary by the doctor

2. Handing over of case sheet from ward to billing office

3. Case sheet Receiving by billing office

4. Verification by billing dept

5. Generating typed discharge summary

6. Finalisation of bill by billing section

7. Payment by patient attenders and getting billing clearance

8. Waiting for billing queries and clarifications

9. Waiting for investigations and cross referrals

10. Waiting for transport arrangements by patients

Name;

Department

Designation

Signature

\section{References}

1. Christopher G. Maloney, Douglas Wolfe, MBA ${ }^{2}$ Per H. Gesteland, Joe W. Hales, ${ }^{2}$ and Flory L. Nkoy, ..A Tool for Improving Patient Discharge Process and Hospital Communication Practices: the Patient Tracker.AMIA Annu Symp Proc. 2007; 2007: 493497. Published online 2007.

2. Muhammad Umair Majeed, Thomas Williams, Rachel Pollock, arhat Amir, Martin Liam, Keen S Foong and Chris J Whitaker.. Delay in discharge and its impact on unnecessary hospital bed occupancy.. BMC Health Services Research BMC series \& 2012 12:410..DOI: 10.1186/1472-6963-12-410 Published: 20 November 2012

3. Gijs Hesselink, Marieke Zegers, Myrra VernooijDassen, Paul Barach, Cor Kalkman,.. Improving patient discharge and reducing hospital readmissions by using Intervention Mapping.. BMC Health Services Research. 13 September 2014

4. Fierce Health care Zack BudryK.. March 18, 2016... Hospital discharges: 5 strategies to improve the process and cut readmissions.
5. Ou L, Young L, Chen J, Santiano N, Baramy LS, Hillman K: Discharge delay in acute care: reasons and determinants of delay in general ward patients. Aust Health Rev. 2009, 33: 513-521. 10.1071/AH090513.

6. Soraia Aparecida da Silva ' Flávia Carvalho Botelho, Carlos Faria Santos, Brasil, Faculdade de Medicina. Universidade Federal de Minas Gerais. MG, Brasil. et al.. Reasons for discharge delays in teaching hospitals....6 Rev. Saúde Pública vol.48 no.2 São Paulo Apr. 2014..http://dx.doi.org/10.1590/S0034 8910.2014048004971.. Public Health Practice Original Articles

7. Laura-Maria Peltonen, Louise McCallum4 Eriikka Siirala, Marjaana Haataja, Heljä Lundgrén-Laine6 Sanna Salanterä, et al An Integrative Literature Review of Organisational Factors Associated with Admission and Discharge Delays in Critical Care. Bio Med Research International, Volume 2015 (2015), Article ID 868653 , http://dx.doi.org/10.1155/2015/868653

8. Which Reasons Do Doctors, Nurses, and Patients Have for Hospital Discharge? A Mixed-Methods Study..Dirk T. Ubbink, Evelien Tump, Josje A. Koenders, Sieta Kleiterp, J. Carel Goslings, Fleur E. Brölmann Published: March 13, 2014 http: // dx . doi. org/ 10. 1371/journal.pone.0091333

9. Discharge planning: establishing an effective coordination team. Summerton H. BrJ Nurs. 1998 Nov 12-25; 7(20):1263-7.

10. Wong EL, Yam $\mathrm{CH}$, Cheung AW, Leung MC, Chan FW, et al. (2011) Barriers to effective discharge planning: a qualitative study investigating the perspectives of frontline healthcare professionals. BMC Health Services Res 11: 242. doi: 10.1186/14726963-11-242

11. Ou L, Young L, Chen J, Santiano N, Baramy LS, et al. (2009) Discharge delay in acute care: reasons and determinants of delay in general ward patients. Aust Health Rev 33(3): 513-21. doi: 10.1071/ah090513

12. Ou L, Chen J, Young L, Santiano N, Baramy LS, et al. (2011) Effective discharge planning - timely assignment of an estimated date of discharge. Aust Health Rev 35(3): 357-63. doi: 10.1071/ah09843 Associate Professor, DEpt of HA NMCH , Nellore , A.P *** Asst .Prof, Dept of HA, $\mathrm{NMCH}^{* * * *} \mathrm{PG}$ ( HA), Dept of HA, NMCH

\section{How to cite this article:}

Ramamohan D et al (2017) ' Evaluation Of Discharge Process Of Insurance Versus Paying Category Of Patients In A Hospital', International Journal of Current Advanced Research, 06(05), pp. 3616-3622.

DOI: http://dx.doi.org/10.24327/ijcar.2017.3622.0332 